\title{
Are Health Facilities Providing Quality Care for Newborn and Young Infants in Pakistan?: Findings From a Cross-Sectional Study
}

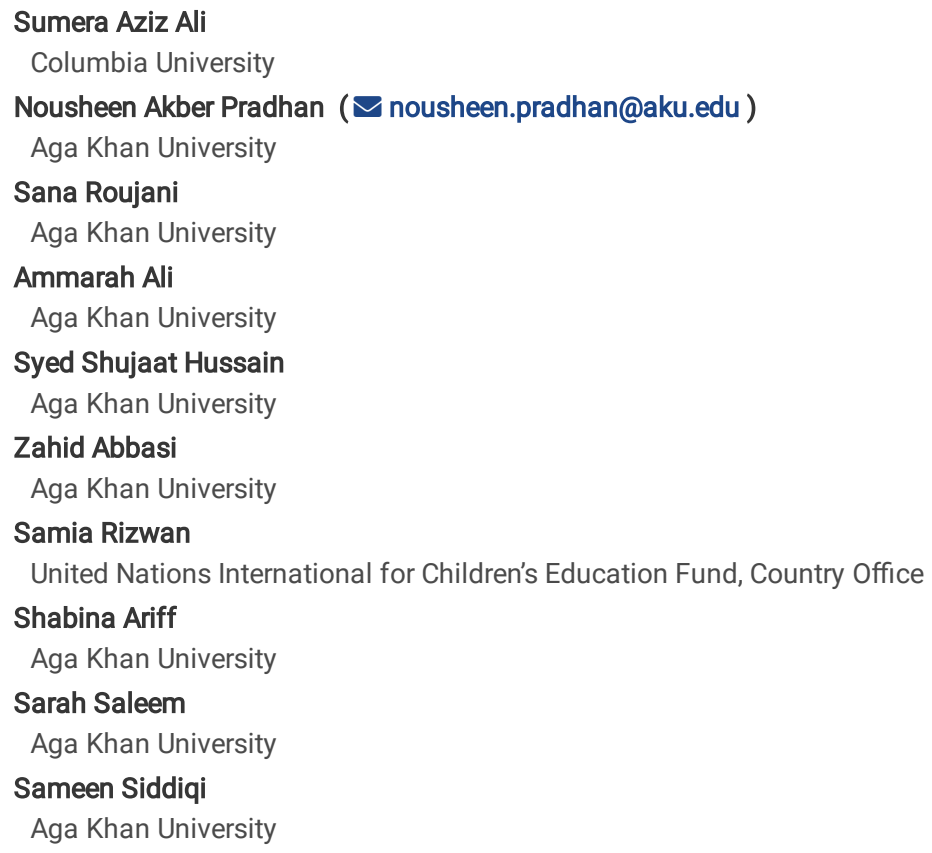




\section{Abstract}

Introduction

Pakistan is considered to be the riskiest place for newborns due to its highest neonatal mortality rate. Securing pregnancy and delivery care may not bring a substantial reduction in neonatal mortality, unless coupled with the provision of essential newborn and inpatient care for sick newborns and young infants (NYIs). We undertook this study to assess the availability and quality of newborn care services provided, and the readiness of inpatient care for NYls in Pakistan.

\section{Methods}

We conducted a cross-sectional study across Pakistan from February to June 2019 in 23 public sector health care facilities providing inpatient care for sick NYIs. We interviewed facility managers and health care providers by using structured questionnaires. We observed facility infrastructure and relevant metrics related to the quality of inpatient care such as types of infant care units and essential equipment, staffing cadre and facility management practices, quality assurance activities, essential services for NYI care, discharge planning and support, quality of NYls care record, and health information system.

\section{Results}

Of the 23 facilities assessed, $83 \%$ had special care units for the sick NYIs, $70 \%$ had newborn intensive care units (NICUs), and $39 \%$ had Kangaroo Mother Care Units (KMCs). Almost $100 \%$ of the facilities had pediatricians, $13 \%$ had neonatologists, and $9 \%$ had neonatal surgeons. Around $61 \%$ and $13 \%$ of the facilities had staff trained in neonatal resuscitation and parental counselling, respectively. About $35 \%$ of the facilities monitored nosocomial infection rates, $39 \%$ were baby-friendly hospitals, and $26 \%$ were accredited. Essential services to diagnose congenital birth defects were offered in only $4 \%$ of facilities. Only $39 \%$ of facilities had received external supervision for NYI care and 17\% reported organizing management team meetings preceding the survey.

\section{Conclusion}

The study has demonstrated important gaps in the quality of newborn care in inpatient settings in the country. This includes dearth of KMCs, inadequate human resources, untrained staff, insufficient facility management practices, lack of inter-disciplinary meetings, and poor maintenance of records for critical newborn outcome indicators leading to compromised quality of care. To avert neonatal mortality in the country, provincial and district governments have to take action in improving inpatient care.

\section{Introduction}

Around 3.3 million newborns die within the first month of their birth, accounting for $41 \%$ of the global burden of under-five mortality with most deaths occurring in low and middle-income countries (LMICs) [1]. Approximately two-thirds of these neonatal deaths occur within the first seven days after birth, mainly on the first day of life [2,3]. Pakistan bears a significant burden of newborn deaths, was unable to reach the Millennium Development Goal of reducing child mortality, and has been considered as the riskiest place to be born, where for every 1,000 newborns, 46 die before the first month of their life [4]. Although the Government of Pakistan (GoP) with the support of many development partners has made efforts to improve maternal and child health by increasing access to antenatal care, facility-based delivery, and strengthening district health systems, these efforts have not made a significant dent in reducing neonatal mortality [5]. The Sustainable Development Goals provide a renewed opportunity to achieve the global target of $12 / 1000$ neonatal deaths, as the GoP aims to achieve universal health coverage by 2030 [6].

Increasing access alone is unlikely to improve neonatal outcomes unless coupled with efforts to improve the quality of inpatient care for sick newborns and young infants (NYIs) [7-10]. Several studies have consistently recognized that the quality of neonatal inpatient care is a major concern [9, 11]. While improving access and quality of inpatient care is crucial to achieving the objectives of the Every Newborn Action Plan (ENAP) of $\leq 10$ newborn deaths per 1000 live births by 2035 [12], numerous bottlenecks exist in LMICs such as inadequate infrastructure, scarcity of health workforce, inadequate budget, and lack of appropriate payment mechanisms [13]. The United Nations International Children's Fund (UNICEF) has been actively supporting the GoP in its endeavours to reduce neonatal mortality by establishing district level Sick Newborn Care Units (SNCUs) across the country.

The Aga Khan University (AKU) working in partnership with UNICEF conducted a study to assess the readiness and quality of inpatient care for NYIs provided in public sector hospitals across Pakistan. The study identified gaps and challenges and proposed evidence-informed recommendations that are required to be prioritized and implemented to achieve the Sustainable Development Goal 3 by 2030 (in particular target 3.2).

\section{Material And Methods}

UNICEF in partnership with the GoP has established 38 sick newborn care units (SNCUs) in public sector hospitals across all four provinces (Sindh, Punjab, Baluchistan, and Khyber Pakhtunkhwa (KPK) and two administrative regions (Azad Jammu \& Kashmir (AJK) and Gilgit Baltistan (GB)) of Pakistan. We conducted a cross-sectional study during the year 2019 in 23 [61\%] of these public sector healthcare facilities to assess inpatient care for newborns and young children (0-59 days of age), using a purposive sample in consultation with provincial health departments. The eligibility was contingent on distribution across all provinces and regions and provision of round the clock inpatient care for NYls at these facilities.

Data was collected using a set of structured questionnaires and survey tools designed by UNICEF for a multi-country study on the same subject. These tools were pre-tested in a non-study facility to assess the flow, coherence, and sequence of questions, and required amendments were made. Two data collection 
teams, each with one paediatrician and two doctors were trained over one week on the data collection tools. These teams surveyed sampled health care facilities and were closely supervised and supported in the field by the principal investigator and co-investigator.

The data collection elements included interviews with health care providers and direct observations of the services provided. After assessing the eligibility criteria and receiving written informed consent from the facility in-charge (supervisors and managers), the study team familiar with the national (Urdu) or local language, administered the questionnaire to the facility in-charge and service providers who were actively engaged in the provision of care to NYIs.

The structure of the facility assessment tool was based on health system components/building blocks defined by the World Health Organization (WHO) [10]. Processes of care at the facilities were assessed using eight domains listed in the WHO maternal and newborn health quality of care framework[14]. Direct observations included assessment of facility infrastructure and relevant metrics related to the quality of inpatient care, staffing, availability and functionality of equipment, facility management practices, quality assurance activities, essential services for NYI care, and discharge planning and support. In addition, we explored quality assurance activities such as monitoring of nosocomial infection rates as well as facility practices in terms of workforce and financial management.

Medical records of inpatient NYls of 0-59 days were reviewed to determine the pattern and quality of routine monitoring of the newborns at birth that included medical history and physical examination, and primary and secondary diagnosis. Reports and records related to the number of live births, perinatal deaths, neonatal deaths, and average bed occupancy were collected for the previous three months. Lastly, the research team assessed health workers' qualifications, working conditions and experience, and their training in related specialties.

The completed data was entered in the standardized computerized data entry templates under the supervision of a data manager. Descriptive statistics, frequencies, proportions, and average percentages were estimated to determine characteristics of the health care facilities using statistical software SPSS (version 19.0). Service readiness analyses covered domains such as type of infant care units, staff and their capacity building, quality assurance, availability of interventions for NYI care, discharge planning and support, and facility management practices.

\section{Results}

The distribution and level of hospitals included in the study is provided in Table 1. The results were analysed and are presented under the following domains: (i) type of infant care units and availability of essential equipment; (ii) staffing cadre, training of the staff and facility management practices; (iii) quality assurance activities related to NYI care; (iv) availability of interventions for NYls care and discharge planning and support; (v) quality of newborn and young infants' records; and (vi) health information systems.

\section{Types of infant care units and availability of essential equipment}

Of the total 23 facilities assessed, 83\% had SNCUs, 70\% had NICUs, and 40\% had KMC Units (Table 1 A). Three different types of units are described below;

NICUs provide the services that require close monitoring (e.g., blood transfusions, incubator or radiant warmer care) and keep patients who are considered in critical condition. A neonatologist is ideally available 24 hours in NICUs. SNCU provides various levels of interventions and treatments for sick infants. If a facility has a NICU, the SNCU usually care for moderately ill infants providing treatments, but not at the level offered in NICUs, and not with the intensive monitoring expected in a NICU. These patients would not be as critical as those in the NICU and would not require the level of monitoring a NICU should provide. On the other hand, KMC unit has beds for the mother or another person to comfortably provide skin-to-skin care, and providing specific assistance so that the infant can receive breast milk (either through breastfeeding or alternative methods)[15].

Differences were also observed among different levels of hospitals. The national referral hospital was equipped with all three types of care units. The six provincial referral hospitals assessed had SNCUs in all, NICU in 83\%, and KMC units in 33\%. Of the 14 District Headquarter Hospitals (DHQs) hospitals assessed, $78 \%$ had SNCUs, $64 \%$ had NICUs, and $36 \%$ had basic care or KMC unit.

There were variations observed among provinces/federal territories as regards the availability of different types of infant care units. All facilities in AJK, ICT, and Punjab; $60 \%$ in KPK; and $50 \%$ of the facilities in Sindh and Baluchistan were equipped with NICUs, while GB did not have the same type of unit. The availability of KMC was reported from the only surveyed facility in Islamabad Capital Territory (ICT) and most (83.3\%) of facilities in Punjab, while none of the surveyed facilities in the federal territories and KPK had KMC units. However, a quarter of the facilities in Sindh province and half of the facilities in Baluchistan were equipped with KMC units. The functionality of all three units was also gauged during field site observations.

The majority of the surveyed facilities were equipped with essential equipment required for the inpatient care of NYls (Figure 1). However, less than half of the facilities (43\%) notified carrying out preventive and corrective maintenance for equipment.

\section{Staffing cadre, training of the staff, and facility management practices}

All 23 facilities reported having at least one paediatrician. Only 13\% of the facilities had neonatologists and neonatal nurse specialists, as illustrated in Table 1A. Among all provinces and regions, only AJK had a neonatal nurse specialist, while the availability of neonatal surgeons and paediatric retinal specialist was reported from few (9\%) facilities in Sindh and Baluchistan.

Figure 2 depicts capacity-building initiatives for staff working in the assessed health care facilities in three domains for NYI care: (1) neonatal resuscitation, (2) advanced care for newborn, and (3) parental counselling on infant deaths. Of the three domains, $61 \%$ of the facilities had trained staff in neonatal resuscitation, $43 \%$ in advanced care for small and sick newborns, and $13 \%$ in parental counselling on infant death. External supervision for improved facility management during the last three months was reported by $39 \%$ of all facilities. In the context of this study, external supervision was considered by the

Page $3 / 11$ 
supervisory visits paid by District Health Management and/ Provincial Health Management representative to ensure smooth adherence of standards being followed at the facility level [15].

There were 4 or $17 \%$ of the 23 facilities assessed that conducted management team meetings. The practice of inter-disciplinary team meetings was reported by $30 \%$ of management personnel. This was mostly being practiced in AJK and Punjab. Lastly, the assessment showed that more than half ( $57 \%$ ) of the facilities reported control over budgetary matters (Table 2).

\section{Quality assurance activities related to NYI care}

All 23 facilities were assessed for four dimensions of quality of care: (1) monitoring quality of care indicators specific to NYI care, (2) monitoring of nosocomial infections, (3) accreditation/ certification, and (4) designated baby-friendly hospitals (Table 2).

Overall, $70 \%$ of the facilities reported monitoring any quality care indicators for performance measurement, while $35 \%$ of facilities reported monitoring of nosocomial infections, with variations across provinces. All facilities assessed in AJK, $50 \%$ in Punjab, and $40 \%$ in KPK had a system in place for the monitoring of nosocomial infections. It was found that slightly more than a quarter $(26 \%)$ of the facilities reported participating in an accreditation or certification program (at the time of survey or in the past). As regards to baby-friendly hospital (in terms of either the certification and external validation of the implementation of policies and implementation of practices for the protection, promotion and support for breastfeeding, as defined by WHO/UNICEF BabyFriendly Hospital Initiative[15], nearly $40 \%$ of the facilities were designated as baby-friendly; inclusive of a facility in ICT and $75 \%$ of the surveyed facilities in Baluchistan and Sindh each.

\section{Availability of interventions for NYI care and discharge planning and support}

The assessment demonstrated that diagnostic services and treatment of severe neonatal illnesses were available in the majority (87\%) of the surveyed facilities; however, antepartum/intrapartum interventions were available in only $39 \%$ of the facilities (Figure 3 ). Basic interventions for sick NYIs care and practices for infant safety were reported from $43 \%$ and $65 \%$ of the facilities respectively (Figure 3 ). All required services to diagnose congenital birth defects/disorders for newborns were available in only Pakistan Institute of Medical Sciences Hospital, Islamabad. The percentages shown in Figure 3 represent only those facilities that reported $100 \%$ of the services under all five essential services and interventions for NYIs care.

Around $52 \%$ of the surveyed facilities reported a system or guidelines for the discharge plan for home care of the NYls. More than one third (35\%) of the surveyed facilities reported providing strategies for promoting adherence after infant discharge (Table 3). A system to support home care for NYIs after discharge via community health workers was reported by only $13 \%$ of the facilities.

Variations were reported among provinces with regards to the discharge planning for NYI care. Both surveyed facilities in AJK, $75 \%$ in Baluchistan, $50 \%$ in Sindh, and $40 \%$ in KPK had a system in place for discharge planning. A similar system was found to be lacking in GB. All the surveyed facilities in ICT and AJK reported having strategies for promoting adherence after infant discharge; however, one facility in Baluchistan (1/4), 2/5 in KPK, 2/6 in Punjab reported strategies for promoting adherence after infant discharge. Facilities in Sindh and GB lacked attention on post-discharge care for infants.

\section{Quality of newborn and young infants' records}

A total of 184 records of NYIs at 1-2 days $(n=79)$ and 3-59 days $(n=105)$ were reviewed to determine routine monitoring of NYIs and information recorded for assessing quality and planning for discharge. Most (73\%) of reviewed records of NYIs at 1-2 days had information on the birth weight, temperature recording (52\%), while only a quarter (25\%) of the observed records documented danger signs. In addition, the documentation of the congenital anomalies and Appearance, Pulse, Grimace, Activity, and Respiration (APGAR) scores were observed in one-third of the reviewed records. (Table 4)

Of the 105 records of NYIs (3-59 days old) reviewed for the documentation related to clinical examination at the time of admission, the majority ( $96 \%$ ) of records had the information on infants' age; $79 \%$ on patient's history and $48 \%$ had any note of pregnancy history. Over $70 \%$ of records had also captured information on the mode of delivery. Overall, $57 \%$ of reviewed records captured information on transfer/referral notes from the referring unit at the time of admission. (Table 4)

\section{Health information system}

Assessment of facility practices for collating and monitoring information showed that $83 \%$ of the surveyed facilities routinely submitted electronic or paperbased hospital management information system reported to an external body, such as the directorate of health services or a regional technical department. Only $9 \%$ of the surveyed facilities reported compiling the reports without submission to higher levels. In addition, $87 \%$ of the surveyed facilities reported submitting birth information to the National Vital Statistics. Regarding newborn health monitoring, $78 \%$ of the facilities reported monitoring any newborn/ neonatal care indicators. Almost all facilities reported having data accessible for neonatal deaths and stillbirths in separate units, however, none of the subunits within facilities had consolidated information.

\section{Discussion}

There were almost 4.6 million new births in Pakistan in the year 2018, of which over 200,000 died within the first month of their life. This situation is unacceptable and requires a multipronged approach if the numbers must improve. One such intervention is to ensure the availability of and access to good quality inpatient care for NYI, especially in secondary and rural hospitals of LMICs such as Pakistan. This study was undertaken principally to assess the availability, quality, and readiness of services, and inpatient care for young and sick infants in multiple hospitals of the country and is part of a larger multicounty initiative by UNCIEF. 
Pakistan is a large country and has over 700 large and small public sector hospitals across the country. Although the study was carried out on a small sample of 23 public hospitals, it is illustrative of the prevailing issues surrounding NYI care in the country. The study found that infant care units such as NICUs and SNCUs were generally available in the surveyed facilities. However, the availability of KMC units remained low across the district and provincial hospitals, indicating important gaps in the provision of essential newborn care services at these facilities. Although policymakers, researchers, and key stakeholders in Pakistan have highlighted KMC as an essential component to save newborn lives [3], this has not been translated into functioning KMC units at health care facilities. Given the evidence to-date, KMC units are significant in reducing neonatal mortality and have been identified as a crucial element of newborn health initiatives by ENAP [16]. A meta-analysis of KMC and neonatal outcomes among low birth weight newborns, compared to conventional care KMC was associated with $36 \%$ lower mortality (RR $0.64 ; 95 \%[C l] 0.46,0.89)$, thereby warranting interventions for its scale-up.

Alongside infrastructural support, the availability of essential equipment is also significant to improve the quality of NYI care. Our findings reveal that most of the facilities were equipped with the necessary equipment. This showed good progress in the available stock of required supplies and equipment, as earlier most of the neonatal care settings in the government hospitals of Pakistan were not sufficiently equipped[17]. The major challenge of the functionality of the equipment however remains and there were gaps reported about the preventive and corrective maintenance of equipment, where less than half of facilities reported carrying out preventive and corrective maintenance of equipment. Such findings are comparable with a study conducted in Ethiopia, which showed that almost all of the facilities providing newborn care were not supported by biomedical engineers [18], who are required for the preventive and corrective maintenance of the equipment.

Adequate stock and skill mix of the health workforce to provide neonatal services is of paramount importance towards improving the quality of NYIs care. Our study findings highlighted the shortage of specialist staff (neonatologist, neonatal surgeon, and neonatal nurse specialists) mainly at DHQs. The findings regarding the shortage of skilled newborn care is comparable to the studies conducted in other LMICs [19-21]. These findings are also consistent with previous literature suggesting that an inadequate number of trained and competent staff is a major challenge in NICUs across Pakistan[22]. The scarcity of the specialist staff in neonatal care at the district level could be attributed to the inadequacy in the sanctioned positions (especially, neonatologists and neonatal surgeons) at the health care facilities and inadequate financial resources.

A further challenge was insufficient attention to the capacity building of staff through continuing education. This was particularly seen in areas of parents' counselling on infant death and advanced care for small and sick newborns. Similar findings have also been reported from previous studies in Pakistan and other countries, highlighting the lack of staff training as a serious concern[23, 24]. The underlying reasons could be inadequate resource allocation for staff training at the provincial and district health department. However, these factors need to be explored further, and specialized neonatal care training of existing paediatricians and nurses needs to be planned and implemented accordingly if good quality NYls care is to be provided.

Interdisciplinary team meetings among neonatal care specialists (paediatricians, obstetricians, radiologists, nursing specialists, and pharmacists) are essential to improve coordination, identify needs, and to enhance the plan of care for any particular patient[25]. This was a major gap identified by the study, which was predominantly due to the low priority given to such activities, and the excessive flow of patients in the public health care facilities.

Most of the reviewed records had captured information on vital signs and birth weight, however, information on danger signs and APGAR scoring remained undocumented in most of the NYIs records. An earlier study from Pakistan also shows that staff working in the NICUs are inadequately trained to recognize danger signs, which might be an obstacle for them to record the required information $[24,26]$. The identified gaps in the reporting of important indicators in newborn health could be ascribed to the absence of a standardized mechanism of documentation at the SNCUs across the secondary and tertiary care hospitals in Pakistan.

The major strength of this cross-sectional survey was the assessment of health care facilities in the public health sector across the entire country with a focus on inpatient newborn care, which is the first of its kind at the national level. Second, we used standardized tools to collect information about inpatient NYI care services across public health care facilities. Also, the survey covered all public health facility types, including national, provincial referral hospitals as well as facilities at the district level, which provided a holistic view of inpatient NYI care in the public health sector of Pakistan. Despite the relatively small number of health facilities, it adequately represented the public health care system of the country. The absence of health facilities providing similar care in the private sector was a limitation of the study.

\section{Conclusions}

The study has demonstrated important gaps towards improving the quality of newborn care in the inpatient settings in public hospitals of the country. This includes a shortage of KMC units, dearth of specialized neonatal care workforce, inadequacy in staff training, poor attention on inter-disciplinary meetings, and inadequate documentation of the important parameters for neonatal health.

Four actions are recommended to ensure service readiness and to enhance the quality of inpatient NYI care. These include - (i) Establish KMC units at the district and provincial hospitals with adequate supplies and equipment; (ii) Deploy specialized staff at DHQ hospitals that include neonatologists, neonatal surgeons, and neonatal nurses; (iii) Build on the job capacity of health care providers to provide them with hands-on skills in neonatal care management; (iv) Strengthen a standardized reporting format to capture information on important parameters of newborn care with adequate external supervision.

\section{List Of Abbreviations}

Aga Khan University AKU

Appearance, Pulse, Grimace, Activity, and Respiration APGAR

Page 5/11 
Azad Jammu \& Kashmir AJK

District Headquarter Hospital DHQ

Every Newborn Action Plan ENAP

Gilgit Baltistan GB

Government of Pakistan GoP

Islamabad Capital Territory ICT

Kangaroo Mother Care KMC

Khyber Pakhtunkhwa KPK

Low and Middle-Income Countries LMICs

Newborn Intensive Care Units NICUs

Newborns and Young Infants NYIs

Sick Newborn Care Units SNCUs

United Nations International for Children's Education Fund, Country Office,

Pakistan UNICEF

World Health Organization WHO

\section{Declarations}

\section{Ethics approval and consent to participate}

Ethical clearance was obtained from AKU's Ethics Review Committee, as well as the National Bioethics Committee. Ethical considerations were duly taken care of during the training and conduct of the study. All respondents were approached for their informed verbal and written consent prior to data collection. Confidentiality of the information was maintained throughout and data was saved in a secure manner. All methods were carried out in accordance with relevant guidelines and regulations.

\section{Consent for publication}

Not applicable.

\section{Availability of data and materials}

The datasets used and/or analyzed during the current study are available from the corresponding author on reasonable request.

\section{Competing interests}

The authors declare that they have no competing interests.

\section{Funding}

The UNICEF has funded the study.

\section{Authors' contributions}

\section{Acknowledgements}

We are highly grateful to the support extended in the conduct of the study from the Ministry of National Health Services, Regulation and Coordination, Islamabad Pakistan and all Provincial and District Health Departments. We would also like to acknowledge all those who supported during the data collection. This includes Dr.Waqar Khowaja, Dr. Hafsa Yousaf, Dr. Quanita Ziauddin, Mr. Mukhtiar Ahmed Channa, Miss Abida Noor Muhammad, Miss Sehrish Salim, Miss Sumaira Fatima Qurban Ali, Miss Ghazal, Dr. Fasahat Ahmed Butt Dr.Farwa Haider, and Dr. Babar Shahid. And Ms. Ghazal Moin who assisted in the data analysis. Acknowledgements are also due to UNICEF Country Office Pakistan that financial and technically supported this study.

\section{Authors' information}

\section{Affiliations}

Department of Epidemiology, Columbia University New York, USA 
Dr. Sumera Aziz Ali; MBBS; MSc; FCPS; PhD Scholar

\section{Department of Community Health Sciences, Aga Khan University, Pakistan}

Ms. Nousheen Akber Pradhan; BScN; MSc

Dr. Sana Roujani; BDS; MSc

Dr. Ammarah Ali; BDS; MSc

Dr. Syed Shujaat Hussain, MBBS; FCPS; MSc Student

Mr. Zahid Abbasi, BSc; M. Phil

Dr. Sarah Saleem; MBBS; DCH, MSc, FCPS

Dr. Sameen Siddiqi; MBBS; MSc; FCPS; FFPH; DrMed

\section{United Nations International for Children's Education Fund}

Dr. Samia Rizwan; MBBS; FCPS

\section{Department of Paediatrics and Child Health}

Dr. Shabina Ariff; MBBS;FCPS

\section{Authors' Contributions}

S.A. designed the study with technical input from S.S. and Sa.S. S.A. and N.P. executed the study, provided field supervision and drafted the manuscript. S.R., A.A., S.H., Z.A. assisted in the data collection, data analysis and also provided input in the manuscript. Sa.R provided funding, technical support and also reviewed the manuscript. Sh.A., S.S., and Sa.S. provided technical input during the design and conduct of the study and provided critical input in the manuscript. All authors have reviewed the manuscript.

\section{References}

1. Organization WH: Neonatal and perinatal mortality: country, regional and global estimates: World Health Organization; 2006

2. Lawn JE, Cousens S, Zupan J, Team LNSS: 4 million neonatal deaths: when? Where? Why? The lancet 2005, 365(9462):891900.https://doi.org/https://doi.org/10.1016/S0140-6736(05)71048-5.

3. Yoshida S, Rudan I, Lawn JE, Wall S, Souza JP, Martines J, Bahl R: Newborn health research priorities beyond 2015. The Lancet 2014, 384(9938):e27e29.https://doi.org/https://doi.org/10.1016/S0140-6736(14)60263-4.

4. UNICEF for every child. Every Child Alive. The urgent need to end newborn deaths. In.; 2018

5. Velikkakam T, Fiuza JA, Gaze ST: Overview of hookworm infection in humans. In: Neglected Tropical Diseases-South Asia. edn.: Springer; 2017: 121-135

6. Ministry of National Health Services R, Coordination: National Health Vision Pakistan 2016-2025. 2016

7. Lim SS, Dandona L, Hoisington JA, James SL, Hogan MC, Gakidou E: India's Janani Suraksha Yojana, a conditional cash transfer programme to increase births in health facilities: an impact evaluation. The Lancet 2010, 375(9730):2009-2023.https://doi.org/https://doi.org/10.1016/S0140-6736(10)60744-1.

8. Ekirapa-Kiracho E, Waiswa P, Rahman MH, Makumbi F, Kiwanuka N, Okui O, Rutebemberwa E, Bua J, Mutebi A, Nalwadda G: Increasing access to institutional deliveries using demand and supply side incentives: early results from a quasi-experimental study. BMC international health and human rights 2011, 11(1):1-14.https://doi.org/https://doi.org/10.1186/1472-698X-11-S1-S11.

9. Jan AZ, Ahmad S, Zahid SB: Clinical audit of admission pattern and its outcome in a neonatal ICU. Gomal J Med Sci 2013, 11(1):31-36

10. Youssry MA, Radwan AM, Gebreel MA, Patel TA: Prevalence of Maternal Anemia in Pregnancy: The Effect of Maternal Hemoglobin Level on Pregnancy and Neonatal Outcome. Open Journal of Obstetrics and Gynecology 2018, 8(07):676

11. Begum N: Clinical Profile of Neonatal Admission and Hospital Outcome in a Tertiary Care Hospital of Dhaka City.

12. Fund WHOaUNIfCsE: Every Newborn: An action plan to end preventable newborn deaths Geneva: World Health Organisation. 2014,[cited 2014 September 2014]. In.

13. Moxon SG, Lawn JE, Dickson KE, Simen-Kapeu A, Gupta G, Deorari A, Singhal N, New K, Kenner C, Bhutani V: Inpatient care of small and sick newborns: a multi-country analysis of health system bottlenecks and potential solutions. BMC pregnancy and childbirth 2015, 15(2):1-

19.https://doi.org/https://doi.org/10.1186/1471-2393-15-S2-S7.

14. Organization WH: Standards for improving quality of maternal and newborn care in health facilities. 2016

15. Youssry MA, Radwan AM, Gebreel MA, Patel TAJ: Prevalence of maternal anemia in pregnancy: the effect of maternal hemoglobin level on pregnancy and neonatal outcome. Open Journal of Obstetrics Gynecology 2018, 8(7):676-687.https://doi.org/10.4236/ojog.2018.87072.

16. Organization WH: Every newborn: an action plan to end preventable deaths. 2014

17. Mohammad A: Government hospitals lack equipment to save pre-mature babies. In.: Daily Times; 2007

Page $7 / 11$ 
18. Ameha A, Engida E, Sylla M, Worku N, Oulare M, Legesse H, Gelaw B, Negash Y, Tadesse L, Selemon M: Readiness of Primary Health Care Units in Addressing Facility-based Newborn Care in Ethiopia. Ethiopian Medical Journal

2019(3).https://doi.org/https://emjema.org/index.php/EMJ/article/view/1399.

19. Neogi S, Khanna R, Chauhan M, Sharma J, Gupta G, Srivastava R, Prabhakar P, Khera A, Kumar R, Zodpey S: Inpatient care of small and sick newborns in healthcare facilities. Journal of Perinatology 2016, 36(3):S18-S23.https://doi.org/https://doi.org/10.1038/jp.2016.186.

20. Andriantsimietry SH, Rakotomanga R, Rakotovao JP, Ramiandrison E, Razakariasy MER, Favero R, Gomez P, Dao B, Bazant E: Service availability and readiness assessment of maternal, newborn and child health services at public health facilities in Madagascar. African journal of reproductive health 2016, 20(3):149-158.https://doi.org/DOI: 10.29063/ajrh2016/v20i3.19.

21. Berendes S, Lako RL, Whitson D, Gould S, Valadez JJ: Assessing the quality of care in a new nation: South Sudan's first national health facility assessment. Tropical Medicine \& International Health 2014, 19(10):1237-1248.https://doi.org/https://onlinelibrary.wiley.com/doi/full/10.1111/tmi.12363.

22. Kenner C, Hirani SAA: Safety issues in neonatal intensive care units in Pakistan. Newborn and Infant Nursing Reviews 2008, 8(2):6971.https://doi.org/https://doi.org/10.1053/j.nainr.2008.03.006.

23. Ariff S, Soofi SB, Sadiq K, Feroze AB, Khan S, Jafarey SN, Ali N, Bhutta ZA: Evaluation of health workforce competence in maternal and neonatal issues in public health sector of Pakistan: an assessment of their training needs. BMC health services research 2010, 10(1):319.https://doi.org/https://link.springer.com/article/10.1186/1472-6963-10-319\#citeas.

24. Vesel L, Manu A, Lohela TJ, Gabrysch S, Okyere E, Ten Asbroek AH, Hill Z, Agyemang CT, Owusu-Agyei S, Kirkwood BR: Quality of newborn care: a health facility assessment in rural Ghana using survey, vignette and surveillance data. BMJ open 2013, 3(5).https://doi.org/http://dx.doi.org/10.1136/bmjopen2012-002326.

25. Rice DL: Implementing a Monthly Interdisciplinary Team Meeting to Promote Optimal Outcomes for High-Risk Obstetric Patients and Their Newborns. Journal of Obstetric, Gynecologic \& Neonatal Nursing 2013, 42:S13-S14.https://doi.org/https://doi.org/10.1111/1552-6909.12065.

26. Mufti P, Setna F, Nazir K: Early neonatal mortality: effects of interventions on survival of low birth babies weighing 1000-2000g. Journal-Pakistan Medical Association 2006, 56(4):174.https://doi.org/https://mail.jpma.org.pk/PdfDownload/658.

\section{Tables}

Table 1: Distribution and level of hospitals across provinces and regions

\begin{tabular}{|c|c|c|c|c|c|c|}
\hline S.No & Provinces and Administrative Regions & National referral hospital & Provincial referral hospitals & District hospitals & $\begin{array}{l}\text { Tertiary } \\
\text { care hospitals }\end{array}$ & Total \\
\hline 1. & Punjab & - & 1 & 5 & - & 6 \\
\hline 1. & Sindh & - & 1 & 1 & 2 & 4 \\
\hline 1. & Khyber Pakhtunkhwa & - & 1 & 4 & - & 5 \\
\hline 1. & Baluchistan & - & 2 & 2 & - & 4 \\
\hline 1. & Islamabad Capital Territory & 1 & - & - & - & 1 \\
\hline 1. & Azad Kashmir & - & - & 2 & - & 2 \\
\hline 1. & Gilgit and Baltistan & - & 1 & - & - & 1 \\
\hline Total & & 1 & 6 & 14 & 2 & 23 \\
\hline
\end{tabular}

The table presents the distribution of different level of hospitals across four provinces and two federal territories in Pakistan.

Table $1 \mathrm{~A}$ is on the following page.

Table 1 A: Availability of infrastructure and staff for neonatal care $(n=23)$ 


\begin{tabular}{|c|c|c|c|c|c|c|c|c|}
\hline \multirow[t]{2}{*}{ S. No } & \multirow[t]{2}{*}{ Level of facility } & \multirow{2}{*}{$\begin{array}{l}\text { Number of facilities } \\
\text { surveyed }\end{array}$} & \multicolumn{3}{|c|}{ Infant care units } & \multicolumn{3}{|l|}{ Trained staff } \\
\hline & & & NICUs & SCUs & $\begin{array}{l}\text { BCU/ } \\
\text { KMC }\end{array}$ & Paediatrician & Neonatologist & $\begin{array}{l}\text { Neonatal nurse } \\
\text { specialist }\end{array}$ \\
\hline 1. & $\begin{array}{l}\text { National referral } \\
\text { hospital }\end{array}$ & 1 & 1 & 1 & 1 & 1 & 1 & 0 \\
\hline 2. & $\begin{array}{l}\text { Provincial referral } \\
\text { hospital }\end{array}$ & 6 & 5 & 6 & 2 & 6 & 1 & 1 \\
\hline 3. & District level hospital & 14 & 9 & 11 & 5 & 14 & 1 & 2 \\
\hline 4. & Tertiary care hospital & 2 & 1 & 1 & 1 & 2 & 0 & 0 \\
\hline \multicolumn{2}{|c|}{ Total (percent) } & 23 & $16(70 \%)$ & $19(83 \%)$ & $9(39 \%)$ & $23(100 \%)$ & $3(13 \%)$ & $3(13 \%)$ \\
\hline
\end{tabular}

This table highlights the availability of infrastructure and trained staff at 23 surveyed care facilities across four different levels of the hospitals in the country.

Table 2. Facility management and quality assurance practices at SNCUs $(n=23)$

\begin{tabular}{|c|c|c|c|c|c|c|c|c|c|c|}
\hline \multirow{2}{*}{$\begin{array}{l}\text { S. } \\
\text { No. }\end{array}$} & \multirow{2}{*}{$\begin{array}{l}\text { Level of } \\
\text { facility }\end{array}$} & \multirow{2}{*}{$\begin{array}{l}\text { Number } \\
\text { of } \\
\text { facilities } \\
\text { surveyed }\end{array}$} & \multicolumn{4}{|c|}{ Management and Supervision } & \multicolumn{4}{|c|}{ Quality of Care Attributes } \\
\hline & & & $\begin{array}{l}\text { External } \\
\text { supervision* }\end{array}$ & $\begin{array}{l}\text { Management } \\
\text { team } \\
\text { meetings* }\end{array}$ & $\begin{array}{l}\text { Interdisciplinary } \\
\text { team meetings* }\end{array}$ & $\begin{array}{l}\text { Budgetary } \\
\text { flexibility }\end{array}$ & $\begin{array}{l}\text { Monitoring } \\
\text { quality of } \\
\text { care } \\
\text { indicators }\end{array}$ & $\begin{array}{l}\text { Monitoring } \\
\text { nosocomial } \\
\text { infection }\end{array}$ & $\begin{array}{l}\text { Accreditation/ } \\
\text { certification }\end{array}$ & $\begin{array}{l}\text { Designat } \\
\text { Baby- } \\
\text { friendly } \\
\text { facility }\end{array}$ \\
\hline 1. & $\begin{array}{l}\text { National } \\
\text { referral } \\
\text { hospital }\end{array}$ & 1 & 0 & 0 & 0 & 1 & 1 & 1 & 0 & 1 \\
\hline 2. & $\begin{array}{l}\text { Provincial } \\
\text { referral } \\
\text { hospital }\end{array}$ & 6 & 3 & 2 & 2 & 3 & 4 & 2 & 0 & 3 \\
\hline 3. & $\begin{array}{l}\text { District } \\
\text { level } \\
\text { hospital }\end{array}$ & 14 & 5 & 1 & 5 & 8 & 10 & 5 & 5 & 3 \\
\hline 4. & $\begin{array}{l}\text { Tertiary } \\
\text { care } \\
\text { hospital }\end{array}$ & 2 & 1 & 1 & 0 & 1 & 1 & 0 & 1 & 2 \\
\hline \multicolumn{2}{|c|}{$\begin{array}{l}\text { Total (percent) } \\
\text { distribution) }\end{array}$} & 23 & $9(39 \%)$ & $4(17 \%)$ & $7(30 \%)$ & $13(57 \%)$ & $16(70 \%)$ & $8(35 \%)$ & $6(26 \%)$ & $9(39 \%)$ \\
\hline
\end{tabular}

*Whether meetings were held at least once every quarter.

The table presents findings on four key practices related to management and supervision, alongside four key quality of care attributes for newborns and young infants across the surveyed facilities in four different levels of hospitals in Pakistan.

Table 3. Discharge planning, patient support and case reviews for neonatal care $(n=23)$

\begin{tabular}{|c|c|c|c|c|c|c|c|c|}
\hline \multirow[t]{2}{*}{ S.No } & \multirow{2}{*}{$\begin{array}{l}\text { Level of } \\
\text { facility }\end{array}$} & \multirow{2}{*}{$\begin{array}{l}\text { Number of } \\
\text { facilities } \\
\text { surveyed }\end{array}$} & \multicolumn{3}{|c|}{ Discharge Planning and Patient Support } & \multicolumn{3}{|c|}{ Case Reviews } \\
\hline & & & $\begin{array}{l}\text { System for } \\
\text { discharge } \\
\text { planning }\end{array}$ & $\begin{array}{l}\text { Linkages } \\
\text { with } \\
\text { CBWs }\end{array}$ & $\begin{array}{l}\text { Strategies to promote } \\
\text { adherence after discharge }\end{array}$ & $\begin{array}{l}\text { Patient } \\
\text { case } \\
\text { reviews* }\end{array}$ & $\begin{array}{l}\text { Near } \\
\text { miss } \\
\text { events** }\end{array}$ & $\begin{array}{l}\text { Perinatal or } \\
\text { neonatal death } \\
\text { reviews*** }\end{array}$ \\
\hline 1. & $\begin{array}{l}\text { National } \\
\text { referral } \\
\text { hospital }\end{array}$ & 1 & 0 & 0 & 1 & 1 & 0 & 1 \\
\hline 2. & $\begin{array}{l}\text { Provincial } \\
\text { referral } \\
\text { hospital }\end{array}$ & 6 & 3 & 0 & 3 & 5 & 3 & 1 \\
\hline 3. & $\begin{array}{l}\text { District level } \\
\text { hospital }\end{array}$ & 14 & 9 & 3 & 4 & 8 & 5 & 6 \\
\hline 4. & $\begin{array}{l}\text { Tertiary care } \\
\text { hospital }\end{array}$ & 2 & 0 & 0 & 0 & 2 & 1 & 2 \\
\hline \multicolumn{2}{|c|}{ Total (percent) } & 23 & $12(52 \%)$ & $3(13 \%)$ & $8(35 \%)$ & $16(70 \%)$ & $9(39 \%)$ & $10(43 \%)$ \\
\hline
\end{tabular}


*A case review is a formal meeting where information about a current or discharged patient is presented, usually by the primary physician for that patient, and issues related to diagnosing, treating, and improving the outcome are discussed. Suggestions from peers are sought.

** Near-misses are newborns that almost died at birth.

*** Perinatal death reviews include meetings where information about stillbirths and infants born alive but who died within 7 days is gathered and presented.

This table illustrates the performance of 23 surveyed facilities on discharge planning and patient support and reported practices on case reviews across four levels of hospitals in Pakistan.

Table 4. Review of newborn and young infants' records at sick newborn care units $(n=23)$

\begin{tabular}{|c|c|c|c|c|c|c|c|c|c|c|c|}
\hline \multirow[t]{3}{*}{ S. No } & \multirow[t]{3}{*}{$\begin{array}{l}\text { Level of } \\
\text { facility }\end{array}$} & \multirow{3}{*}{$\begin{array}{l}\text { Number } \\
\text { of } \\
\text { records } \\
\text { reviewed }\end{array}$} & \multicolumn{6}{|c|}{$\begin{array}{l}\text { Documentation for newborns' assessment parameters } \\
(n=79)\end{array}$} & \multicolumn{3}{|c|}{$\begin{array}{l}\text { Documentation for admissior } \\
(n=105)\end{array}$} \\
\hline & & & $\begin{array}{l}\text { Birth } \\
\text { weight }\end{array}$ & $\begin{array}{l}\text { Danger } \\
\text { signs }\end{array}$ & Temperature & $\begin{array}{l}\text { Congenital } \\
\text { abnormalities }\end{array}$ & $\begin{array}{l}\text { Apgar } \\
\text { score }\end{array}$ & $\begin{array}{l}\text { Number } \\
\text { of } \\
\text { records }\end{array}$ & $\begin{array}{l}\text { Infant } \\
\text { age }\end{array}$ & $\begin{array}{l}\text { Transfer/referral } \\
\text { note }\end{array}$ & Dia \\
\hline & & & & & & & & reviewed & & & \\
\hline 1. & $\begin{array}{l}\text { National } \\
\text { Referral } \\
\text { Hospital }\end{array}$ & 5 & 5 & 5 & 5 & 5 & 4 & 5 & 5 & 5 & 5 \\
\hline 2. & $\begin{array}{l}\text { Provincial } \\
\text { Referral } \\
\text { Hospital }\end{array}$ & 20 & 18 & 6 & 10 & 7 & 12 & 34 & 34 & 18 & 30 \\
\hline 3. & $\begin{array}{l}\text { District } \\
\text { Level } \\
\text { Hospital }\end{array}$ & 45 & 26 & 7 & 18 & 10 & 7 & 56 & 53 & 27 & 52 \\
\hline 4. & $\begin{array}{l}\text { Tertiary } \\
\text { Care } \\
\text { Hospital }\end{array}$ & 9 & 9 & 2 & 8 & 0 & 5 & 10 & 9 & 10 & 8 \\
\hline \multicolumn{2}{|c|}{ Total (percent) } & 79 & $58(73 \%)$ & $20(25 \%)$ & $41(52 \%)$ & $22(28 \%)$ & $28(35 \%)$ & 105 & $101(96 \%)$ & $60(57 \%)$ & 951 \\
\hline
\end{tabular}

The table highlights findings on the documentation practices for newborn assessment (on five important aspects) and documentation practices for admission history and physical examination at 23 inpatient care settings (on six aspects) across four different levels of hospitals in Pakistan.

\section{Figures}

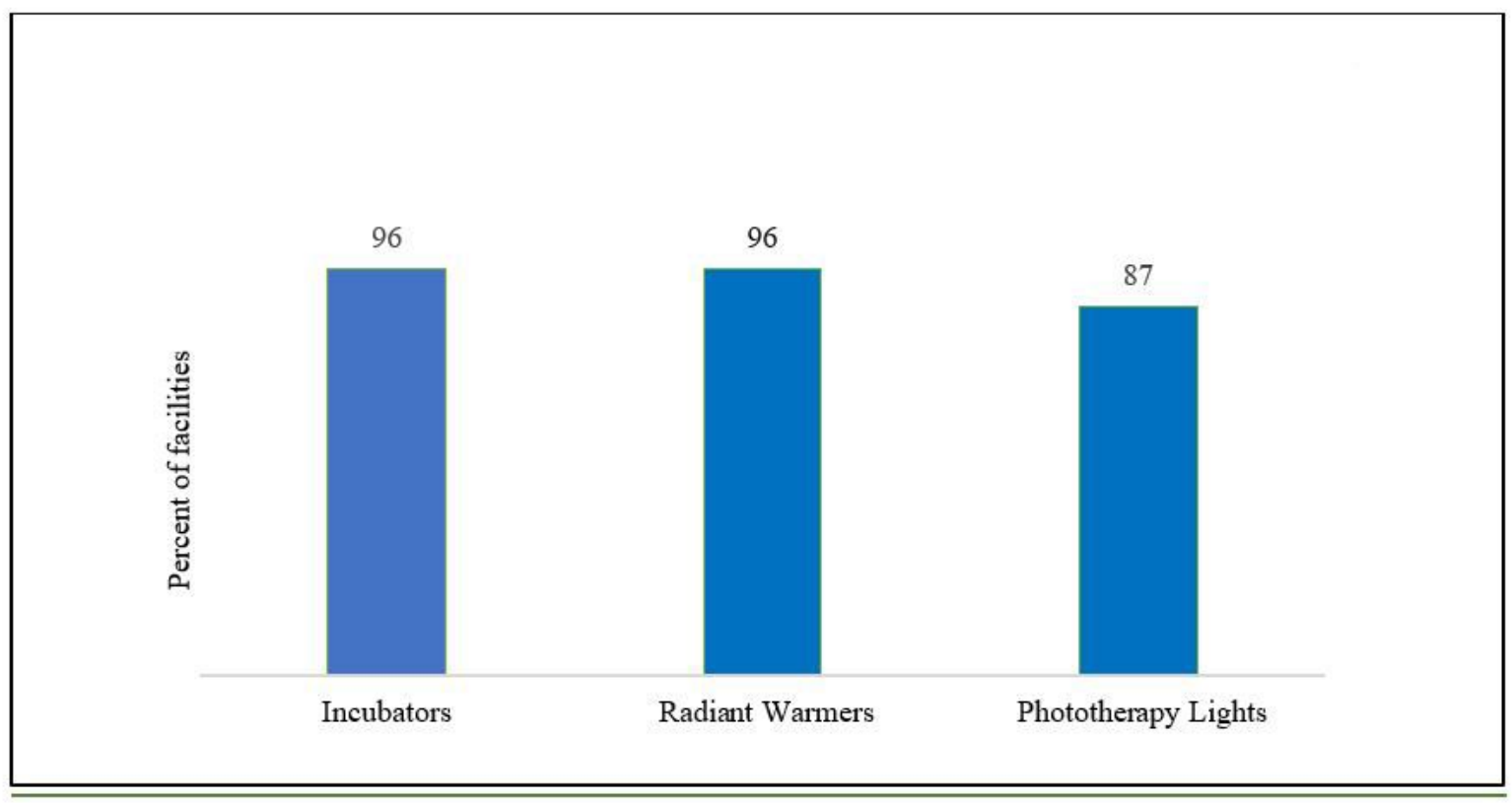

Figure 1

Percent of facilities with the availability of availability of essential equipment for the care of newborn and young infants ( $n=23$ ) Legend: Figure 1 depicts the percentage of facilities with the availability of three essential equipment (incubators, radiant warmers and phototherapy lights) for newborn and young infants 
across 23 inpatient care facilities in the country.

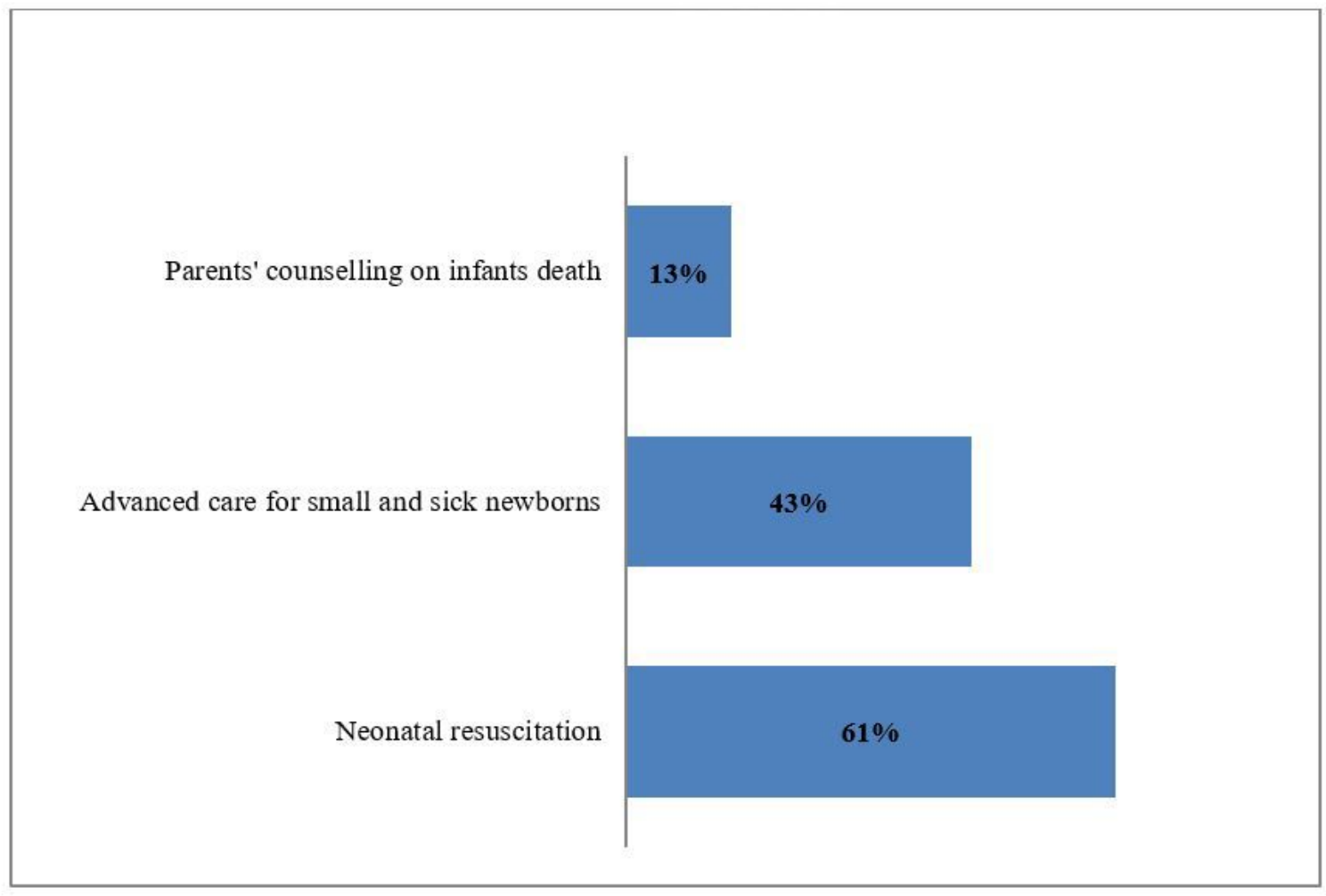

\section{Figure 2}

Percent of facilities reported to conduct staff training on newborns and young infants care $(n=23)$ Legend: Figure 2 exhibits findings reported from 23 inpatient care facilities in Pakistan on staff training related to three important aspects for newborn and young infants care i.e., neonatal resuscitation, advanced care for small and sick newborns and parents' counseling on infants' death.

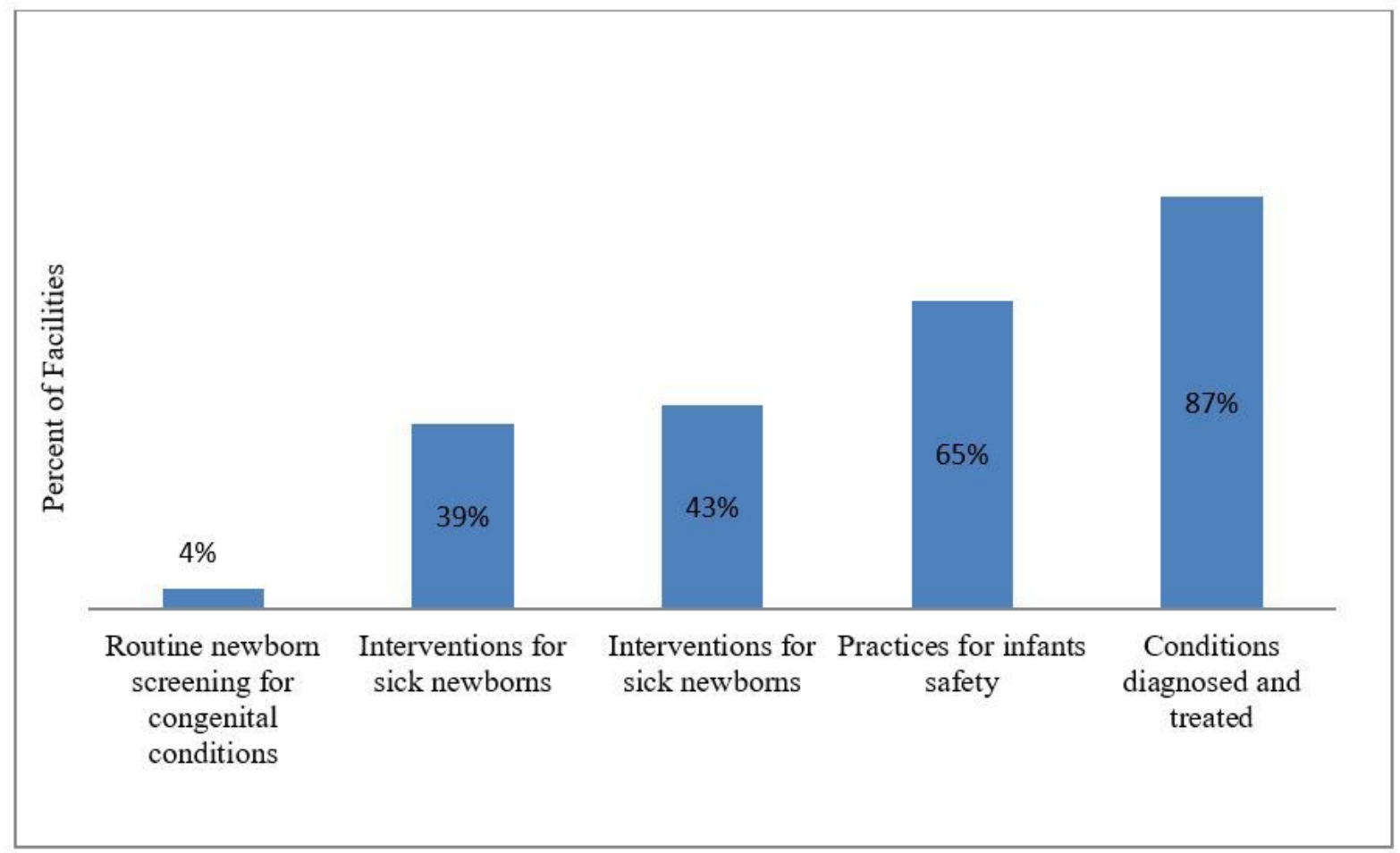

Figure 3

Percent of facilities reported to have essential services and interventions for newborns and young infants care ( $n=23)$ Legend: Figure 3 informs percent of facilities reported to have five essential services and interventions for newborns and young infants care across 23 surveyed health care facilities in Pakistan. 